\title{
INFECCIÓN POR LISTERIA MONOCYTOGENES Y EMBARAZO
}

*Diana Novoa Ch. MD**,Adda Piedad Rozo MD*

\section{Resumen}

Se presenta el caso de dos pacientes admitidas al servicio de ginecología y obstetricia del Hospital de San José a quienes se les diagnosticó infección intrauterina por Listeria monocytogenes con buen resultado perinatal.

Palabras clave: listeriasis, infección intrauterina.

Abreviaturas: LM, Listeria monocytogenes; UCI, unidad de cuidados intensivos.

\section{Introducción}

La LM es un cocobacilo gram positivo que constituye una causa importante de infección, originando en el ser humano una enfermedad llamada listeriasis en especial en mujeres embarazadas, recién nacidos e inmunosuprimidos. Esta bacteria tiene distribución amplia en la naturaleza y debido a su resistencia puede encontrarse en el suelo, los vegetales o como parte de la flora fecal de muchos mamíferos. También se ha aislado de vegetales crudos, leches, pescado, pavo y carne ya sea fresca o procesada, pollo o res. El porcentaje de aislamientos oscila entre 15 y $70 \%$, por lo que se considera que la exposición a alimentos contaminados es relativamente alta ${ }^{1,2}$

No existe certeza sobre las vías de infección, se supone que su transmisión sea a través de alimentos contaminados con materias fecales provenientes de reservorios animales, humanos o ambientales, como el suelo. La patología humana puede darse en el con-

Fecha recibido: septiembre 29 de 2006 - Fecha aceptado: diciembre 15 de 2006

* Residente IV Servicio de ginecología y obstetricia, Hospital de San José.

* Instructora de ginecología, Fundación Universitaria de Ciencias de la Salud, Hospital de San José. texto de una gestación o inmunosupresión; embarazada, feto y recién nacido son los más susceptibles.

\section{Presentación de casos}

Caso 1: se trata de una paciente de 24 años de edad, primigestante, sin antecedentes infecciosos que cursa en el momento del ingreso con embarazo gemelar monocorial biamniótico de 34 semanas y un cuadro clínico de aproximadamente tres días de evolución de cefalea frontal, fiebre cuantificada en 38 a $39^{\circ} \mathrm{C}$, astenia y adinamia. No hay manifestaciones respiratorias ni gastrointestinales, pero se decide hospitalizar en la unidad de alto riesgo para estudio y manejo de síndrome febril sin foco aparente. Se solicita parcial de orina, cuadro hemático, frotis de flujo vaginal y PCR, los cuales son negativos para infección.

Sin embargo, la paciente cursa con picos febriles vespertinos y episodios de taquicardia materna sin sensibilidad uterina ni taquicardia fetal asociada. Las monitorias fetales son reactivas sin evidencia de actividad uterina y perfil biofísico $8 / 8$; se toma ecografía obstétrica que evidencia embarazo gemelar monocorial biamniótico con crecimiento concordante con la fecha de la última regla. Al tercer día de hospitalización la paciente manifiesta sintomatología de la vía 
aérea dada por aumento de la frecuencia respiratoria, tos y expectoración hemoptoica, por lo que se decide realizar radiografía de tórax que muestra infiltrados algodonosos diseminados en ambos campos pulmonares con tendencia a la consolidación. La evolución es tórpida, con desaturación progresiva y marcado trabajo respiratorio; se interconsulta a la UCI quienes la ingresan para manejo de falla respiratoria aguda con intubación orotraqueal, ventilación mecánica y monitoreo de signos vitales. Se lleva a cesárea de urgencia obteniendo dos recién nacidos vivos de sexo masculino; el primero de $1.850 \mathrm{gr}$, talla $43 \mathrm{~cm}$, apgar 3/5/7 y el segundo, de 1.841 gr., talla $44 \mathrm{~cm}$ y apgar 5/7/9; durante el procedimiento, se encuentra además un abrupcio de placenta del $10 \%$. Los recién nacidos se hospitalizan en la unidad neonatal para observación y vigilancia, y la placenta se remite para estudio histopatológico.

Durante la estancia en UCI requiere manejo con altos parámetros ventilatorios y desarrolla hipotensión, que demanda soporte inotrópico con dopamina y aporte de líquidos endovenosos. El reporte de los hemocultivos es positivo para LM por lo que se decide cambiar manejo antibiótico por ampicilina sulbactam. Se considera cuadro de sepsis por LM con síndrome de respuesta inflamatoria del adulto y compromiso pulmonar dado por infiltrados diseminados en ambos campos pulmonares. Las pruebas de función renal, electrolitos y pruebas de coagulación son normales. Se avisa a pediatría quienes inician manejo antibiótico con cubrimiento para LM a los recién nacidos. Madre e hijos tienen una evolución favorable y se dan de alta sin complicaciones.

El reporte definitivo de patología es placenta con infección por LM.

Caso 2: paciente de 38 años, primigestante, con antecedentes personales negativos quien asistió por primera vez a la institución cursando con un embarazo de 36 semanas, con controles prenatales positivos y presentando actividad uterina, por lo que se atiende parto vaginal eutósico y se obtiene recién nacido con un peso de $2.090 \mathrm{~g}$ talla $49 \mathrm{~cm}$ y apgar $7 / 8 / 9$ sin alteraciones.

Madre y recién nacido se dan de alta hospitalaria a las doce horas posparto, pero el lactante reingresa al cuarto día por presentar hipoactividad, disminución de la tolerancia a la vía oral y ligero tinte ictérico. Es examinado por el servicio de pediatría donde encuentran un paciente en malas condiciones generales, taquicárdico, hipotenso y con pobre succión. Se decide hospitalizar con diagnóstico de sepsis neonatal temprana y se inicia manejo con ampicilina, gentamicina y por inestabilidad hemodinámica y aumento del trabajo respiratorio el neonato requiere soporte inotrópico y ventilación mecánica. La placa de tórax muestra infiltrados pulmonares difusos y se toman hemocultivos que son positivos para LM, con posterior evolución hacia la mejoría, tolerancia de la extubación y del retiro de la inotropía; se da de alta sin complicaciones.

La madre consultó de nuevo al servicio de obstetricia al sexto día de posparto por secreción vaginal de mal olor, es valorada y se encuentra una paciente en regulares condiciones generales, subinvolución uterina y loquios turbios; con estos hallazgos más el conocimiento de la hospitalización del neonato con diagnóstico de sepsis por LM se hospitaliza a la paciente y se inicia manejo con ampicilina y metronidazol, al cual responde en forma adecuada con evolución hacia la mejoría, se completan 14 días de manejo intrahospitalario y se decide dar de alta.

\section{Discusión}

La enfermedad bacteriana producida por la LM es poco conocida y su diagnóstico es infrecuente debido a la falta de acuciosidad en su investigación; en EEUU, la LM invasiva confirmada por hemocultivo o cultivo del líquido cefalorraquídeo constituye 7,4 casos por millón habitantes por año. La listeriasis perinatal complica 16 de cada 100.000 nacimientos y el $23 \%$ causan feto muerto los que constituyen el $2 \%$ de las muertes fetales en general. ${ }^{2}$ 
La contaminación alimentaria, tanto en forma de epidemias como de casos esporádicos, en una población de inmunodeprimidos, constituye un factor fundamental para la presentación de la enfermedad. ${ }^{1}$ Se describe también transmisión vía genital en portadoras sanas de la bacteria, con infección ascendente del saco amniótico y el feto, secundaria a rotura prematura de membranas, o bien por infección del feto durante su descenso por el canal de parto, que pudo ser lo que ocurrió con nuestra segunda paciente.

La tasa de portadores sanos varía de un 3\% a un $11 \%$, lo que contrasta con la baja frecuencia con que se detecta la enfermedad: 1 a 3 casos anuales por millón de habitantes. ${ }^{1,2,3} \mathrm{La}$ inmunosupresión local de la interfase maternofetal de la placenta facilita la infección intrauterina tras bacteremia materna asociada, desencadenando una septicemia fetal, excreción del agente bacteriano por la orina fetal al líquido amniótico, deglución de este material infectado y compromiso respiratorio y digestivo fetal. Este mecanismo es el que explica la modalidad temprana de listeriasis neonatal con mayor mortalidad, que varía entre 30 y 50\%. ${ }^{1}$ Esta enfermedad puede producir unas lesiones de aspecto granulomatoso llamado listeriomas, que se pueden encontrar en todos los parénquimas comprometidos e incluso causan microabscesos placentarios, los que al provocar una disminución del flujo útero placentario pueden llevar a la muerte fetal.

La listeriasis en la mujer embarazada se manifiesta en cualquier etapa de la gestación, pero se detecta con mayor frecuencia durante el tercer trimestre, como sucedió en el primer caso; o posparto, como sucedió con la segunda paciente. Los síntomas más frecuentes son estados pseudogripales, fiebre, cefalea, odinofagia, mialgias, dolor lumbar, nauseas y vómito confundiéndose a menudo con fiebre tifoidea o con cuadros de virosis respiratorias que solo requerirían manejo ambulatorio con analgésicos y líquidos. Puede ocasionar aborto, parto prematuro, corioamnionitis, muerte fetal o infección temprana del neonato. Su pronóstico es favorable con manejo antibiótico como se puede observar en los dos casos reportados. ${ }^{2}$
La enfermedad neonatal se clasifica a su vez en temprana si se manifiesta dentro de la primera semana de vida y tardía si ocurre después de los siete días, en una proporción estadística de $2 / 3$ a $1 / 3$ respectivamente. ${ }^{2}$ La modalidad tardía de la enfermedad se asocia con parto a término sin complicaciones. $\mathrm{Su}$ patogenia es incierta, aunque se le ha atribuido a la infección del RN a través de su paso por el canal de parto o por transmisión horizontal en el ambiente nosocomial. ${ }^{3}$ Existe una mayor probabilidad de meningitis con una letalidad cercana al $50 \%$, y se observa también conjuntivitis y síndrome de dificultad respiratoria. ${ }^{4}$

El diagnóstico definitivo se realiza a través de cultivos seriados positivos para LM en sangre, líquido cefalorraquídeo o líquido amniótico. Esta bacteria posee similitudes morfológicas con difteroides y estreptococos, precisando de pruebas bioquímicas para su confirmación. Los estudios serológicos no son útiles ni tampoco lo son los cultivos de sitios no estériles, ya que se estima en un 5\% la presencia de portadores sanos y hasta un $70 \%$ en mujeres con diagnóstico de aborto habitual. ${ }^{1,2,5}$

Este agente entra en el diagnóstico diferencial de prematuridad, aborto espontáneo o feto muerto junto al Streptococcus $B$, sífilis congénita y toxoplasmosis, rubéola, citomegalovirus y herpes simple (TORCH). En el caso de aparecer un bacilo Gram positivo en el líquido amniótico de un aborto febril, debe sospecharse la posibilidad de una listeriasis. El tratamiento de elección es ampicilina (150 a $200 \mathrm{mg} / \mathrm{kg} / \mathrm{día}$ ) o penicilina intravenosa, solas o combinadas con aminoglucósidos. Como alternativa se plantea el uso de trimetropim-sulfametoxazol por un período mínimo de tres semanas por vía parenteral.

Se requieren más estudios para determinar la incidencia en nuestra población y prevenir morbimortalidad maternofetal por una infección que la mayoría de las veces no se diagnostica. 


\section{Referencias}

1. Crespo M, Vélez J, Castañeda C. Aislamiento de L. monocytogenes en un hospital de tercer nivel. Colomb Med 1999;30:89-98.

2. Cisternas A, Lagos N, Galstush J. Infección por Listeria Monocytogenes y embarazo con buen resultado perinatal. Rev. Chil. Obstet Ginecol 2002;67(3):237-241.
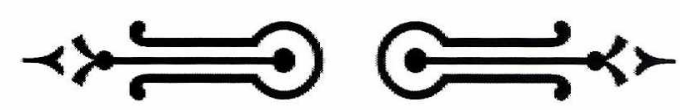

3. Gupta V, Gautam V. Listeriosis in Second Trimester of Pregnancy: case report from India. J Infect Dis 2003;56:6061.

4. Sepulveda C, Oncala E, Guerrero Y. Síndrome de distress respiratorio agudo asociado a listeriosis del embarazo. Enferm Infecc Microbiol Clin 2005; 23:636-637.

5. Benhaim J, Aucouturier Y. Intéret de l' amniocentèse dans lê diagnostic et la prise em charge d'une chorioamniotiteà Listeria monocytogenes. J Infec Diss 2002;12:54-57.

\section{(20) FUNDACIÓN UNIVERSITARIA DE CIENCIAS DE LA SALUD HOSPITAL DE SAN JOSE}

Personería Jurídica No. 10917 Diciembre 1 de 1976 Resolución Ministerio de Educación Nacional No. 0125

Facultad de Instrumentación Quirúrgica

Código ICFES 270246100281100111100

Título otorgado Duración 8 semestres

No. créditos a cursar: 165

Modalidad: presencial
Oficina de admisiones: Carrera 19 No. 8 A-32 Edificio Docente, 1er. piso PBX. $5998977 \cdot 5998842$ TEL. $2019867 \cdot$ TELEFAX 2018938 E-mail: instrumentacion@fucsalud.edu.co hppt: www.fucsalud.edu.co

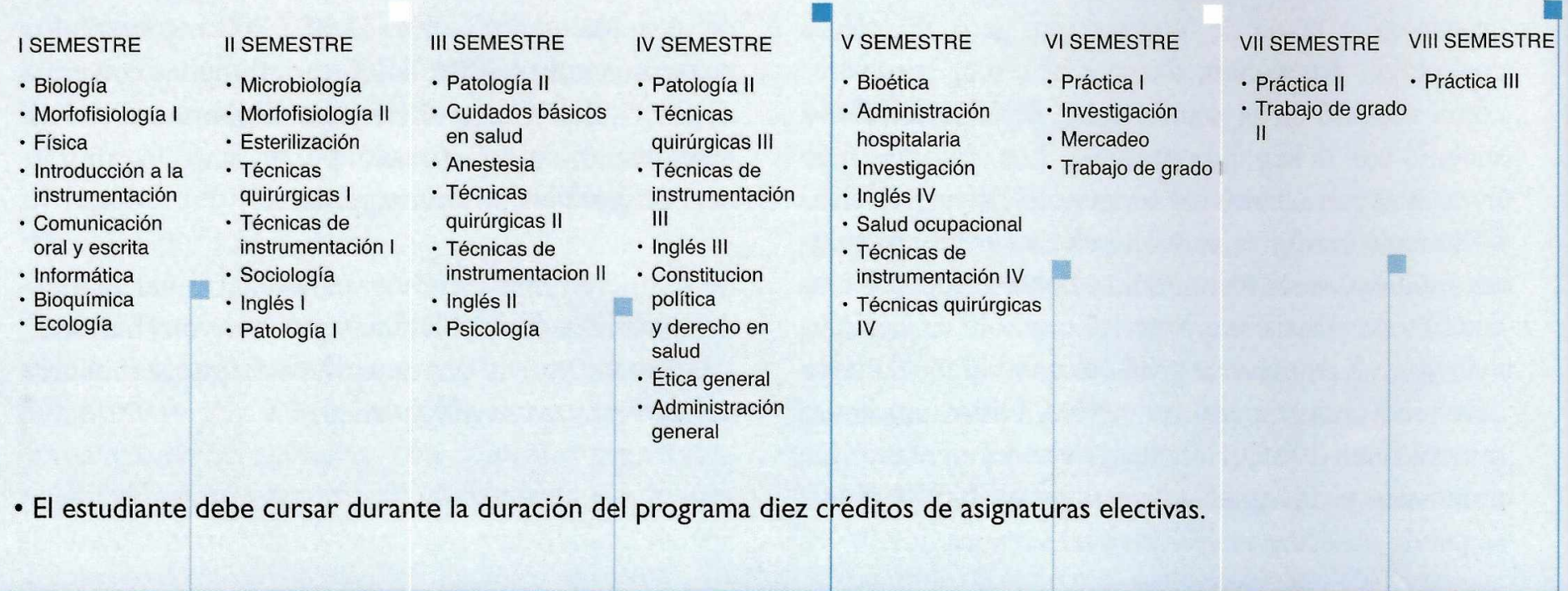

